\title{
Assumption of Ethical Rules of Surrogacy
}

\author{
Jinguo Wang \\ Department of Urology \\ The First Hospital of Jilin University \\ Changchun, China \\ wangjinguolily@163.com
}

\author{
Corresponding author: Na Wang* \\ Department of Anesthesiology \\ The First Hospital of Jilin University \\ Changchun, China \\ wangna080613@163.com
}

\begin{abstract}
Law which is the bottom of the moral requirements embodies basic attitude to surrogacy of the country. While surrogacy legislation is not the same among countries, but they should follow the basic ethical stance was similar. That does not harm the human dignity and maintenance under the premise of human common value system; maximize positive effects of technology of surrogate, trying to passing on the human inherent moral value and the surrogate technology to find a balance between the human society to bring the greatest happiness. It is one characteristic of life ethics how to put forward the ethical rules of surrogacy on the basis of legislation.
\end{abstract}

\section{Keywords-law; life science; surrogacy; ethics}

\section{INTRODUCTION}

For women who can't be pregnant, surrogacy is a desirable way and the only way to let them have a baby of themselves'. The pain suffered by infertile couples is hard to imagine by healthy people. The assisted reproductive technology itself is a kind of helpless choice. Anyway, we all should have a tolerant and understanding attitude. With the continuous development of reproductive technology and improvement of the legislation of surrogacy technology throughout the world, the big trend is changed from being forbidden to open moderately. Because of the specialty of Chinese national conditions, the attitude to surrogacy is relatively more conservative. About surrogacy problems, in addition to establishing and perfecting the legal system, we also must strengthen social ideological and moral construction; enhance people's ideological and moral levels, from two aspects of law and ethics. The problems associated with surrogacy, after all, are ethical and legal problems. Especially the problems related to surrogacy dispute also are far from resolved.

\section{THE SURROGACY SITUATION OF OTHER COUNTRIES}

In Asian countries, there are not set specific law of artificial reproduction technology, but in the execution the law specifically prohibits any forms of surrogacy in Japan. However, in South Korea and Thailand, non-commercial surrogacy is allowed, but for the cognizance of the parentchild relationship between the two countries isn't identical.

Reproductive provisional authority of Hongkong has submitted a regulation on surrogacy. Its basic principle is to prohibit commercial surrogacy, allowing non-commercial surrogacy [1]. The draft is in favor of a surrogacy regulation. The surrogate mother is limited to married women. It prohibits unmarried women to serve as a surrogate mother and also prohibits unmarried women to seek a surrogate mother [2].
Western countries appropriately open surrogacy legislation gradually and surrogacy becomes a mainstream, according to the objective demand of surrogacy. It also makes the western countries to maximize the legislative achievements to realize the dream of infertile couples. For the protection of women and children, commercial surrogacy is banned in many countries. But in practice it is really not easy to put an end to commercial surrogacy [3].

Therefore, countries must from all aspects strengthen the supervision of surrogacy agency and be strict with censorship on surrogacy. Otherwise, legal prohibitions will not exist. Countries such as Britain and America open genetic surrogacy. Overall, Asian countries on surrogacy legislation present a limited open trend from a complete ban.

\section{CHINESE LAWS AND REGULATIONS RELATED TO SURROGACY AND ITS AMENDMENTS}

Chinese government and academia haven't made comprehensive analysis on the actual status of surrogacy in China. Only health department issued a ban. It is far from perfection. Though surrogacy is forbidden by law, but the public's attitude toward it is changed over time [4]. However, because of such an emotional factor and the surrogacy technology should not be leaved aside.

Modern surrogacy technology brought hope to the infertile couples. The market demand of surrogacy is huge. The statistics shows more than ten thousand babies were born every year in China in black market. Because of the huge market demand and the restriction of regular medical institutions, driven by the interests, the underground surrogate companies are overrun. Surrogacy becomes a kind of social chaos. It brings a series of legal problems and social problems. In this context, how to regulate surrogacy through legislation is the problem we have to face.

In China, artificial assisted reproductive technology has a rapid development. At present, there are a lot of domestic medical institutions to carry out the technology services [5]. Supporters claim surrogacy shall be gradually opened up and establish laws to clarify the parent-child relations of surrogacy, inheritance relationships and to resolve contract disputes related problems to make the surrogacy technology a hope for those people who really have reproductive barriers. They say that reproductive rights are a basic human right. There are no problems to the application of modern science and technology to have their own child. It isn't reasonable to deprive of the rights of their children' birth, because of their physical defect. 
A surrogate mother has disciplinary right to own body without affecting social orders. Therefore, non-commercial surrogacy is beneficial to society and others.

If surrogacy is permitted by law, people can get help in normal hospital through legal channels, rather than through a variety of underground illegal intermediary with private deals. It will better safeguard the client, a surrogate mother's health and other legitimate rights and interests.

At the same time, more and more scholars have proposed that surrogacy should be viewed rationally, the implementation of surrogacy technology should be rationally regulated, and the surrogacy demand should be prohibited.

Some medical experts say it is difficult to understand this ban. Since everyone is equal and there is the existing treatment, why do we deprive these people the right of being parents? All of the assisted reproductive technologies at first are in order to solve the infertility problems of the female or male. As a result of the surrogacy technology is developed as a method for the treatment of infertility. Using in vitro fertilization technology, it lets the sperm and egg form embryo, and then transplants it into the womb of a surrogate mother to complete the pregnant process. Reproductive technology provides the possibility, it will have realistic inevitability.

Surrogacy does put forward many new ethical issues, so it is necessary for individuals and society to formulate the corresponding ethical norms. However, some people think that the surrogacy technology is one of the assisted reproductive technologies, so to forbid surrogacy is only likely to affect a few mothers who can't gestate by their own, but it will not affect the development of human assisted reproductive technology. If one day, we have the corresponding laws and a very good market operation order, and then implementation of surrogate technology may be allowed. The management method on the human assisted reproductive technology is discussed by health experts. The experts still believe that although surrogate technology is very mature, the technology is still possible problems in the implementation process, because management rules are fairly backward. The current ban on medical institutions to implement the surrogate technology is in accordance with the reality [6].

A complete ban on surrogacy technology in China is only in the transitional period of emergency, not the entire process. For a total ban on Chinese policies, it is necessary to reconsider. What's more, China is a socialist country; promoting mutual cooperation is the spirit of collectivism. Completely out of altruistic motives, it embodies the spirit of this [7]. Therefore, it is suggested that China should strengthen and perfect the legislation of the surrogacy, implement surrogacy under the control of law and discriminate different forms of surrogacy by law. China should change as soon as possibly to the practice of surrogacy. In reference on academic research, we should draw lessons from foreign legislative surrogate management which accords with the situation of Chinese situation.

\section{ETHICAL RULES OF SURROGACY}

Ethical rule does not harm the human dignity under the premise of human common value system. It maximizes positive effects of surrogate technology, passes on the human inherent moral value. It helps to find a balance between the human society and our tradition to bring the greatest happiness. How to put forward the ethical rules is one characteristic of life ethics on the basis of legislation.

Practical argument is guided by the goals of appropriate means, techniques or strategies, compared with the process of balancing. Through the study and the rational selection of several action plans, the most appropriate approach and operation method can be selected. Its effectiveness is based on experience knowledge, because this expert argumentation is indispensable.

At the same time, if the practical problem involves ethical or moral aspects, moral argument or ethical argument should be conducted first, and then the level of negotiation should be converted. As far as surrogacy is concerned, the feasibility and validity of medical research are practical arguments, which are related to the basis of the standardization of surrogacy.

\section{A. The necessity and feasibility of ethical regulations}

History proves that any abuse of a technology will have adverse effects on the human and the human society. The surrogate technology isn't an exception. Therefore, besides surrogacy law, the ethical and moral constraints should be also strengthened. Ethical regulation has both necessity and feasibility. Morality and law are the necessary social control mechanism. Social moral regulation to a certain level has more advantages than the law and also puts forward higher demand on people's behavior.

To strengthen the ethics rules of surrogacy technology maximizes the value of its good. The feasibility of ethical rules is about several aspects. It is widely acknowledged that the surrogacy is reasonable compensation and altruism. Surrogacy is in ethical justification for sex. In the context of the current technical conditions, surrogate is the only feasible way for infertile couples to have children. The contradiction between autonomy and control is fierce in particular when dealing with ethical problems of private law [8]. The legislative policy on surrogate phenomenon and the traditional view with the conflict disgraceful consideration should be strictly prohibited. Based on the study of welfare economics, market mechanism and personal ethics relations are not irreconcilable, under the constraints in our country. The positive effect of legalization of surrogacy far outweighs its negative effects. Review and reflection on the moral approach does not mean the necessity of the negative controls.

Surrogate technology brings infertility families hope, so they can have their children just like normal family to enjoy family happiness and promote integrity and stability of the family. Assisted reproductive technology should be regardless of gender, skin color, race, economic conditions and fair treatment. The implementation of surrogacy is the practice of the social justice. From the justice perspective of the society, the surrogacy makes every woman have the opportunity to become a mother, makes sterile women equal with other women, because they can use reproductive technology to realize the desire of being a mother. Infertile couples in China 
through surrogacy give birth to a child don't violate the onechild policy [9].

In addition to ethical principles mentioned above, surrogacy must also reflect the following two points which can truly play a positive role. No damage to the interests of the child. The surrogacy can be a useful supplement of natural birth. The key is that the technology guarantees the health of children who can create a good environment of the society and family. In order to make the surrogate children born from discrimination, abuse and entrust, the parents must undertake the obligation. And surrogate children born with marriage have right to inherit their parents or their parents' family's property.

\section{B. The specific ethical program}

The appearance of surrogacy brings a lot of strange ethical and legal issues. The total bans on surrogacy through the administrative rules in our country don't play the desired effect. The public attitudes in China are also relatively tolerant The uncertainty of the parent-child relationship also can be resolved through the legal technology design. With the increasing demand of surrogacy, our country should admit the legality of surrogacy as soon as possible. Combined with social ethics legalization, its boundaries shall be determined. A rigorous and fine rules system which can guarantee citizens' basic rights should be designed.

The birth of the baby has upended the concept of traditional marriage and parental rights. The intergenerational chooses caused by cloning technology are the improper implementation in genetic screening and the genetic discrimination. Genetic rights cause new human rights protection due to the development of science and technology. For example, genetic information can affect employment, insurance and education, etc.

For the protection of genetic information and the need to avoid discrimination, human beings need to produce the right to protect privacy and equality of genes, making it the new content of human rights.

\section{Informed consent.}

The first step of informed consent is to clarify qualification conditions of surrogacy. The implementation process of surrogacy must be strictly controlled to meet certain conditions under which the parties can qualify as the main body of a surrogate mother. A couple must be completely informed and a surrogate subject must be qualified. Both sides must agree to a surrogacy. The surrogate mother should also be in full understanding the nature of the surrogacy, under the premise of legal effect, completely voluntary [9].

A surrogate mother must take many risks in the process of surrogacy. Many couples have to bear the legal risk and money. In order to ensure that they fully understand the risk, rights and obligations before signing the contact, the law requires the physician inform the parties to get to know the artificial reproductive technology, implanted embryos and the risk of multiple pregnancy, the relevant procedure and costs. Health risks rise from the impact of surrogacy, including artificial reproductive process, ovulation drugs, egg and sperm implanted embryos. These are thoughtful to help the parties to know the contract. If one party reneges, it also has legitimacy.

Informed consent includes information to inform the three aspects who understand and voluntarily agreed to all of the items. Surrogacy provides the entrusted consultancy must ensure couples and surrogate mothers understand and be able to make a rational decision. The two sides agree to the surrogate agreement. Confidentiality and privacy should be embodied in the whole process of surrogacy. The medical institutions which provide surrogate service shall not arbitrarily reveal personal information of the people involved. Assisted reproductive technology should maintain and protect the social interests of the couples and families. Good principles including two aspects of no harm and provision of help. In the assisted reproductive technology the medical workers should avoid bringing both sides of husband and wife on physical and mental pain and suffering, but should give the couples and families happiness and joy.

\section{SUMMARY}

The essence of moral regulation lies in the promotion of the value choice and orientation. In the context of the vigorous development of the technology, it has no doubt that surrogacy is consistent with the mainstream trend of development.

Therefore, legislators must be refactor a surrogate system of rules based on the actual situation, in the perspective of feminism jurisprudence and the interests of female standpoint, under the guidance of gender equality .

\section{ACKNOWLEDGMENT}

This research was financially supported by the First Hospital of Jilin University.

\section{REFERENCES}

[1] Rimm J. Booming baby business: Regulating commercial surrogacy in India. University of Pennsylvania Journal of International Law. 2009

[2] June Stephenson. "Women's Roots: The History of Women in Western Civilization". 2000 Posner Richard A. The ethics and economics of enforcing contracts of surrogate motherhood. The Journal of contemporary health law and policy. 1989

[3] Richard A Posner. Regulation of the Market in Adoptions. Boston University Law Review. 1987

[4] Tribe Laurence H. The abortion funding conundrum: inalienable rights, affirmative duties, and the dilemma of dependence. Harvard Law Review. 1985

[5] Goldberg Susan. Medical choices during pregnancy: whose decision is it anyway? Rutgers Law Review. 1989

[6] Ohs Alayna. The power of pregnancy: examining constitutional rights in a gestational surrogacy contract. Hastings constitutional law quarterly. 2004

[7] Epstein RA. Surrogacy: the case for full contractual enforcement. Virginia law review. 1995

[8] Lascarides DE. A plea for the enforceability of gestational surrogacy contracts. Hofstra Law Review. 1997

[9] Lori B. Andrews. Surrogate Motherhood: The Challenge For Feminists. SURROGATE MOTHERHOOD. 1990 